\title{
InP and InGaAs grown on InP substrate by molecular beam epitaxy
}

\author{
Hailong Yu*, Hanchao Gao, Wei Wang, Ben Ma, Zhijun Yin, and Zhonghui Li \\ Science and Technology on Monolithic Integrated Circuits and Modules Laboratory, Nanjing \\ Electronic Devices Institute, Nanjing 210016, China
}

\begin{abstract}
InP and InGaAs epitaxial layers on InP substrates using molecular beam epitaxy (MBE) have been studied. Carrier concentration and mobility of InP and InGaAs are found that are strongly correlated with the growth temperature and V/III ratio. The InGaAs layers using As2 were compared with the layers grown using As4 from a Riber standard cracker cell. When As 4 is used, the highest electron mobility of InGaAs is 3960 $\mathrm{cm}^{2} /(\mathrm{V} \cdot \mathrm{s})$ with the V/III ratio of 65 . When converted to As2, the V/III ratio with the highest electron mobility decreased to 20 . With the arsenic cracker temperature decreased from $950{ }^{\circ} \mathrm{C}$ to $830{ }^{\circ} \mathrm{C}$, the electron mobility increased from $4090 \mathrm{~cm}^{2} /(\mathrm{V} \cdot \mathrm{s})$ to $5060 \mathrm{~cm}^{2} /(\mathrm{V} \cdot \mathrm{s})$.
\end{abstract}

\section{Introduction}

In the past few decades, InP and InGaAs materials have played an increasingly important role in optoelectronic and microelectronic devices. When the composition of gallium in InGaAs changes from 1 to 0 , the energy gap decreases from $1.43 \mathrm{eV}$ to $0.36 \mathrm{eV}$ at room temperature. When the composition of gallium is 0.47 , the lattice constant of InGaAs is the same as that of InP. The $\mathrm{In}_{0.53} \mathrm{Ga}_{0.47} \mathrm{As}$ alloy can be used for radiation detection in the range $0.9 \sim 1.7 \mu \mathrm{m}$. The wavelength response of the compound can be extended up to $3.6 \mu \mathrm{m}$ by increasing the In content[1,2]. The small bandgap energy and superior carrier transport properties of InGaAs have made it widely used in high-speed devices such as heterostructure bipolar transistors (HBTs)[3].

After many years of development, growth of high quality InP and InGaAs epitaxy layers has been achieved by many techniques, such as low pressure metalorganic vapor phase epitaxy, gas source molecular beam epitaxy, solid source molecular beam epitaxy, and metalorganic chemical vapor deposition[4-12].

Compared with other technologies, solid source molecular beam epitaxy (SSMBE) is more suitable for growing thin layers of semiconductors. The molecular or atomic beams of the constituent elements crystallize on a substrate maintained at an elevated temperature under ultra-high vacuum environment. The composition of the grown epilayer and its doping level depend directly on the evaporation rate of the elemental sources. The smoothness of the surface of the film is ensured by a relatively low growth rate, allowing proper surface migration of the atomic species. The source beams can be interrupted very

\footnotetext{
* Corresponding author: hailongyu@163.com
} 
quickly by simple mechanical shutters so that changes in composition and doping can be abrupt on an atomic scale[13-17].

The arsenic source cell in the molecular beam system can provide two forms of arsenic beam flow: $\mathrm{As}_{2}$ and $\mathrm{As}_{4}$. The beam is $\mathrm{As}_{2}$ mode when the cracking zone temperature of arsenic source cell is as high as $950^{\circ} \mathrm{C}$. Although $\mathrm{As}_{2}$ can improve the optical properties of the materials, the high temperature of As cracking zone will bring impurities which increase the carrier concentration of the materials[18-21]. The segregation of gallium and indium atoms easily leads to the degradation of surface morphology[22-25]. The epitaxial temperature has an obvious effect on the crystal quality of InGaAs[26]. The temperaturedependent Hall measurement indicates that in the thick sample solo shallow energy carrier recombination is dominated and polar optical scattering dominates in a larger temperature range[27]. Therefore, it is necessary to study the growth of high quality InP and InGaAs materials by molecular beam epitaxy, and the effects of $\mathrm{As}_{2}$ and $\mathrm{As}_{4}$ on the epitaxy of InGaAs materials.

\section{Experiment}

InP substrate is deoxidized under the protection of phosphorus beam. In the process of InGaAs material epitaxy, excessive arsenic pressure is used to prevent surface degradation The individual growth rate for indium and gallium was determined using reflection high energy electron diffraction (RHEED) intensity oscillations. Growth rates were $0.8 \mu \mathrm{m} / \mathrm{h}$ for all layers. The surface morphology was characterized by an atomic force microscopy (AFM). We adjusted the composition of InGaAs by changing the In cell thermocouple temperature and keeping the Ga cell operated at a constant thermocouple temperature. The thickness of the epitaxial layer for all samples designed was $1 \mu \mathrm{m}$.

\section{Results and discussion}

In the first group of experiments, four samples were InP epitaxial layers grown on semiinsulating InP substrates, which can reduce the effect of substrates on the electrical properties of epitaxial materials. We adjusted growth temperatures from $530^{\circ} \mathrm{C}$ to $620^{\circ} \mathrm{C}$ with $30^{\circ} \mathrm{C}$ step. The curve of carrier concentration and mobility obtained by hall test at room temperature versus epitaxial temperature is shown in Fig.1. In Hall measurement, $0.5 \mathrm{~mm}$-diameter indium balls were used as electrode. The standard and automatic annealing furnace was used for electrode preparation. The automatic and repeatable Hall measurement process can ensure that the epitaxial condition is the only variable in experiments.

The electron mobility was increased from $530^{\circ} \mathrm{C}$ and reached its maximum value 2980 $\mathrm{cm}^{2} /(\mathrm{V} \cdot \mathrm{s})$ at $560^{\circ} \mathrm{C}$. The increase of epitaxial temperature leads to the enhancement of the migration of indium atoms, which further leads to the better incorporation of indium and phosphorus atoms, and improves the electronic properties of the materials. This may be the reason why the mobility increases with the increase of epitaxial temperature. It can be clearly seen from the figure that when the epitaxial temperature increases from $560^{\circ} \mathrm{C}$ to $620^{\circ} \mathrm{C}$, with the increase of carrier concentration, the electron mobility shows a downward trend. The increase of carrier concentration leads to more impurity scattering, which may be the reason for the decrease of electron mobility. The lowest carrier concentration is $1.76 \times 10^{15} \mathrm{~cm}^{-3}$. 


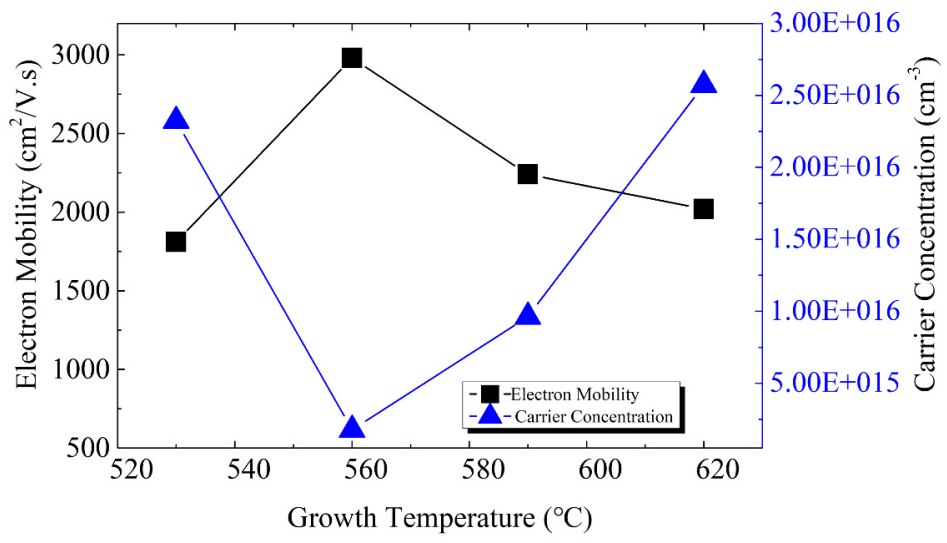

Fig. 1. Electron mobility and concentration on InP epitaxial layers with growth temperature from $530^{\circ} \mathrm{C}$ to $620^{\circ} \mathrm{C}$.

In the second group of experiments, we kept the epitaxial temperature of InP material constant at $560^{\circ} \mathrm{C}$, and changed the V/III ratio from 2 to 15 to study the effect of V/III ratio on the electronic properties of InP material. The curve of carrier concentration and mobility of InP material with V/III ratio is shown in Fig.2. The results clearly showed a significant increase in the carrier concentration from $1.11 \times 10^{15} \mathrm{~cm}^{-3}$ to $1.56 \times 10^{16} \mathrm{~cm}^{-3}$ as the V/III ratio was increased from 4 to 15 . The electron mobility exhibited a corresponding decrease from $3070 \mathrm{~cm}^{2} /(\mathrm{V} \cdot \mathrm{s})$ to $2140 \mathrm{~cm}^{2} /(\mathrm{V} \cdot \mathrm{s})$ following the change in the carrier concentration.

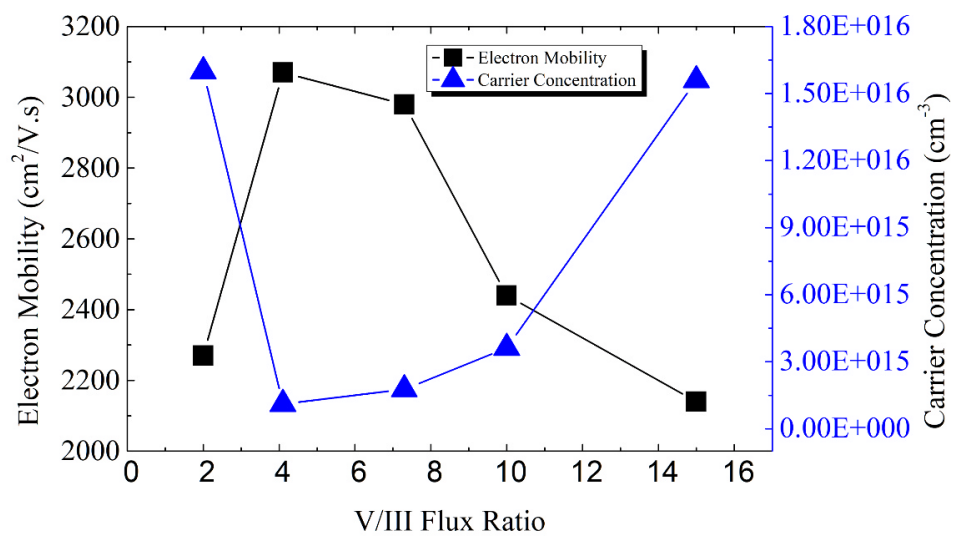

Fig. 2. Electron mobility and concentration on InP epitaxial layers with $\mathrm{V} / \mathrm{III}$ ratio from 2 to 15 .

Fig. 3 and Fig. 4 show the $10 \times 10 \mu \mathrm{m}^{2}$ AFM micrographs obtained on the InP samples with different $\mathrm{V} / \mathrm{III}$ ratio. The InP layer grown at the $\mathrm{V} / \mathrm{III}$ ratio of 4 has a mirror finish with root mean square (RMS) roughness of $0.176 \mathrm{~nm}$. When the V/III ratio is 1.2 , the RMS of the material increases sharply to $3.04 \mathrm{~nm}$, which is mainly due to the insufficient of phosphorus atoms, indium atoms gather into islands. 


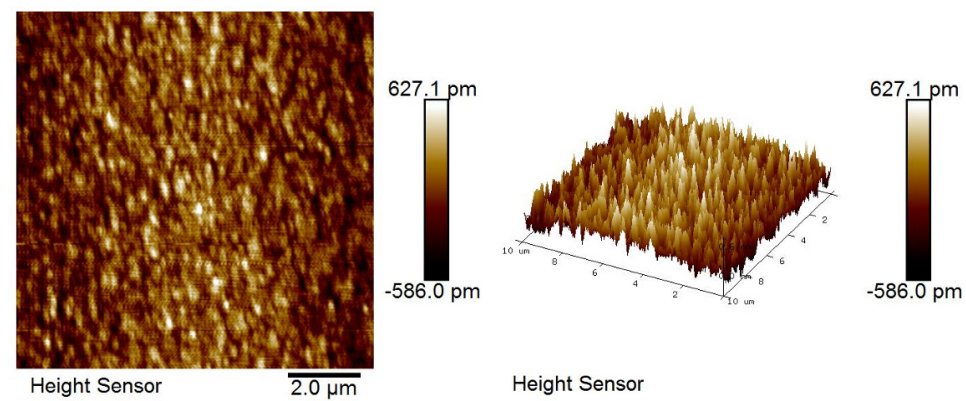

(a) Two dimensional AFM image (b) Three dimensional AFM image

Fig. 3. AFM cartography of $10 \times 10 \mu \mathrm{m}^{2}$ scan area for the InP grown layer when V/III ratio is 4 .
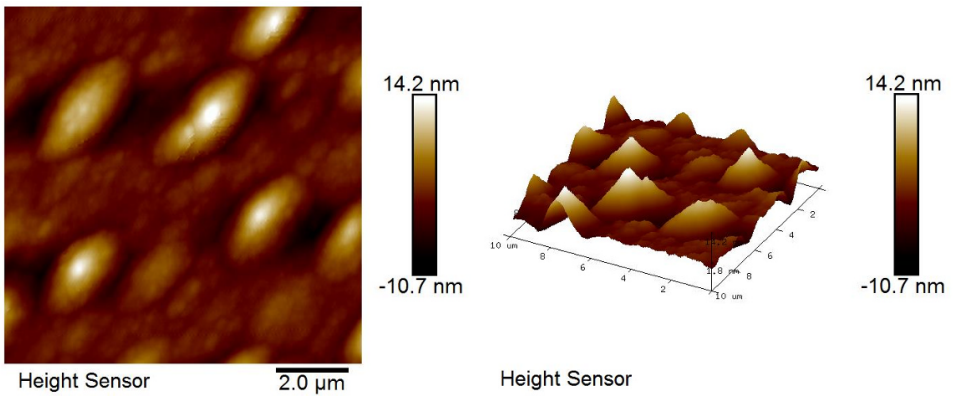

(a) Two dimensional AFM image (b) Three dimensional AFM image

Fig. 4. AFM cartography of $10 \times 10 \mu \mathrm{m}^{2}$ scan area for the InP grown layer when V/III ratio is 1.2.

After obtaining the optimized growth conditions of InP materials, we optimized the growth conditions of $\operatorname{In}_{0.53} \mathrm{Ga}_{0.47}$ As epitaxial layers. A series of $1 \mu \mathrm{m} \operatorname{In}_{0.53} \mathrm{Ga}_{0.47}$ As epitaxial layers were grown at about $0.8 \mu \mathrm{m} / \mathrm{h}$ using $\mathrm{As}_{4}$ on semi-insulating $\mathrm{InP}$ substrates. The growth temperature of $\operatorname{In}_{0.53} \mathrm{Ga}_{0.47}$ As layers changed from $520^{\circ} \mathrm{C}$ to $580^{\circ} \mathrm{C}$ with $20^{\circ} \mathrm{C}$ step. We find that the epitaxial temperature of $\operatorname{In}_{0.53} \mathrm{Ga}_{0.47} \mathrm{As}$ material also has a great influence on the material quality and electrical properties. The relationship between the carrier concentration and mobility of $\operatorname{In}_{0.53} \mathrm{Ga}_{0.47} \mathrm{As}$ at room temperature and the epitaxial temperature is shown in Fig.5. The mobility was increased from $520^{\circ} \mathrm{C}$ and reached its maximum value of $3690 \mathrm{~cm}^{2} /(\mathrm{V} \cdot \mathrm{s})$ at $540^{\circ} \mathrm{C}$. The increase of epitaxial temperature leads to the enhancement of surface migration of indium and gallium atoms and the enhancement of atom incorporation. The scattering of ionizing impurities is suppressed, which improves the mobility of the materials. It can be clearly seen from the figure that when the epitaxial temperature increases from $540^{\circ} \mathrm{C}$ to $580^{\circ} \mathrm{C}$, with the increase of electron concentration, the electron mobility shows a downward trend. The increase of carrier concentration leads to more impurity scattering, which may be the reason for the decrease of electron mobility.

The increase of epitaxial temperature will increase the desorption of indium atoms, resulting in lattice mismatch between InGaAs and InP substrate. We compensate the indium atoms by increasing the temperature of the indium source, so that the InGaAs material and the InP substrate always keep the lattice matching state (Fig6). 


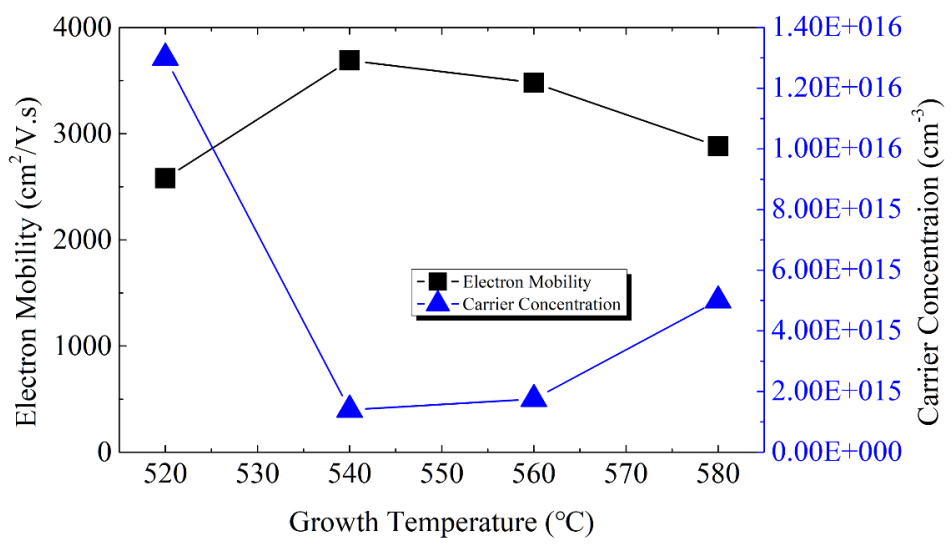

Fig. 5. Electron mobility and concentration on $\mathrm{In}_{0.53} \mathrm{Ga}_{0.47} \mathrm{As}$ epitaxial layers with growth temperature from $530^{\circ} \mathrm{C}$ to $620^{\circ} \mathrm{C}$.

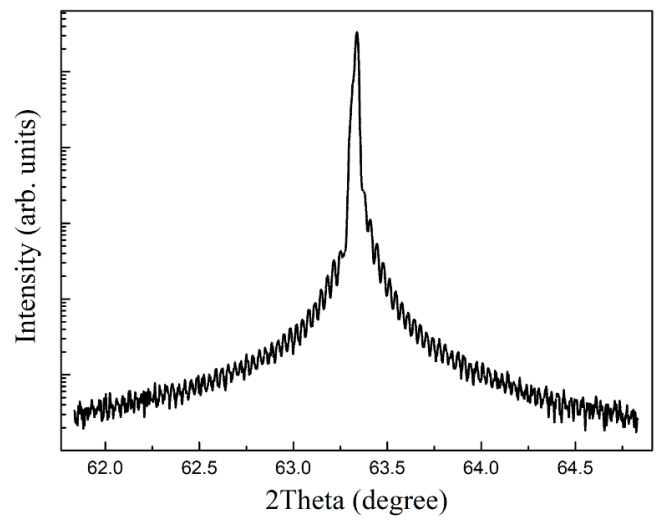

Fig. 6. 20- $\omega$ XRD curve of InGaAs epiatxial layers.

Fig.7 shows the $10 \times 10 \mu \mathrm{m}^{2}$ AFM micrographs obtained on the $\operatorname{In}_{0.53} \mathrm{Ga}_{0.47}$ As epitaxial layers. The $\mathrm{In}_{0.53} \mathrm{Ga}_{0.4} 7 \mathrm{As}$ layer grown at the temperature of $540^{\circ} \mathrm{C}$ has a mirror finish with RMS roughness of $0.201 \mathrm{~nm}$.

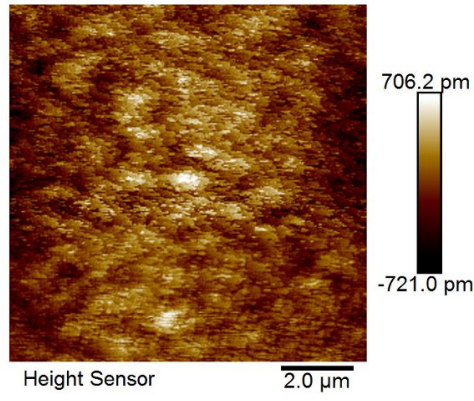

(a) Two dimensional AFM image

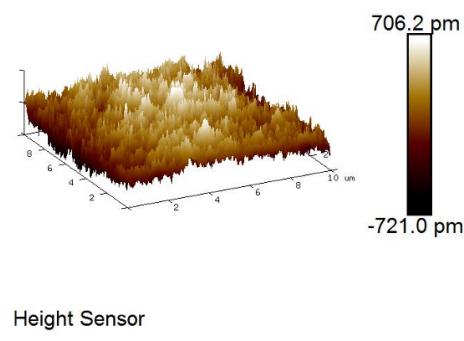

(b) Three dimensional AFM image

Fig. 7. AFM cartography of $10 \times 10 \mu \mathrm{m}^{2}$ scan area for the $\mathrm{In}_{0.53} \mathrm{Ga}_{0.47} \mathrm{As}$ grown with growth temperature of $540^{\circ} \mathrm{C}$.

To find the optimum V/III ratio of the $\mathrm{In}_{0.53} \mathrm{Ga}_{0.47} \mathrm{As}$ layer, we varied the V/III ratio from 20 to 65 . Fig. 8 shows the electron concentration and mobility of $\operatorname{In}_{0.53} \mathrm{Ga}_{0.47} \mathrm{As}$ 
epitaxial layer as a function of V/III ratio. The growth temperature of $\operatorname{In}_{0.53} \mathrm{Ga}_{0.47} \mathrm{As}$ was fixed at $540^{\circ} \mathrm{C}$. As shown in Fig. 8 , when the V/III ratio is between 40 and 65 , both electron mobility and electron concentration are acceptable. We can get the highest electron mobility at the V/III ratio of 65 , which is $3960 \mathrm{~cm}^{2} /(\mathrm{V} \cdot \mathrm{s})$ and lowest carrier concentration at the V/III ratio of 40 , which is $1.4 \times 10^{15} \mathrm{~cm}^{-3}$.

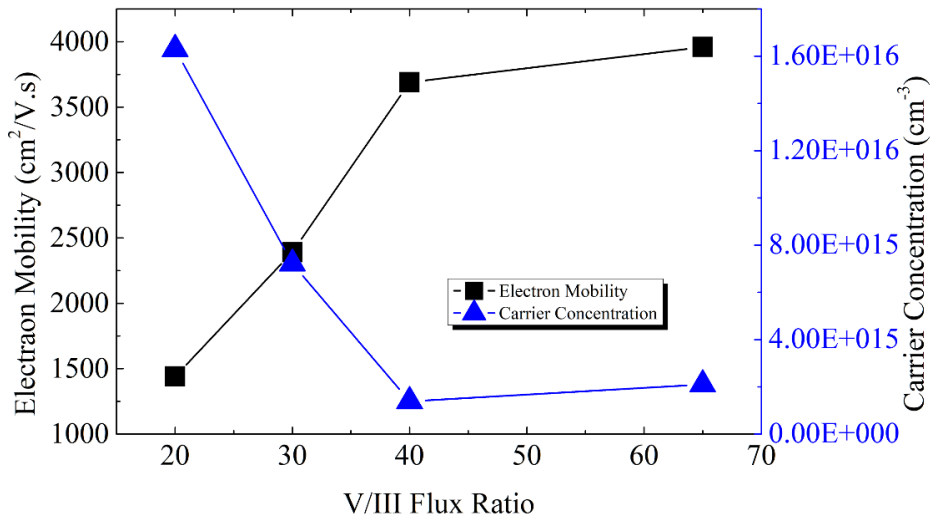

Fig. 8. Electron mobility and concentration on $\mathrm{In}_{0.53} \mathrm{Ga}_{0.47} \mathrm{As}$ epitaxial layers with $\mathrm{V} / \mathrm{III}$ ratio from 20 to 65 .

When V/III ratio is 20, arsenic atoms are in a state of insufficient, which directly leads to the accumulation of group III elements into islands, and the surface roughness of materials is seriously reduced (Fig.9).

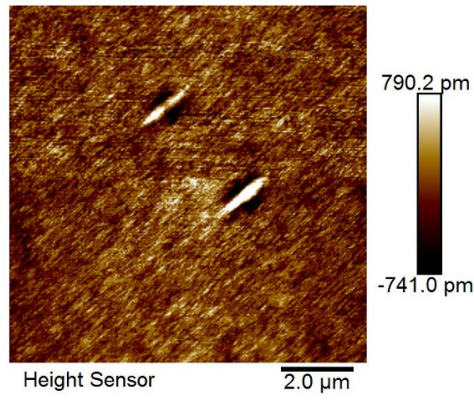

(a) Two dimensional AFM image

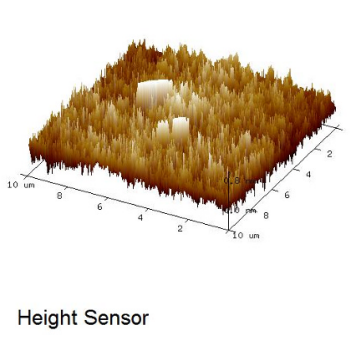

(b) Three dimensional AFM image

Fig. 9. AFM cartography of $10 \times 10 \mu \mathrm{m}^{2}$ scan area for the $\mathrm{In} 0.53 \mathrm{Ga} 0.47 \mathrm{As}$ grown with V/III ratio of 20 .

It is generally believed that the epitaxial mode of $\mathrm{As}_{2}$ is relatively simple and the epitaxial efficiency is higher than that of $\mathrm{As}_{4}$. InGaAs materials grown in $\mathrm{As}_{2}$ mode have relatively few arsenic vacancies, point defects and deep energy levels, so their electrical and optical properties are relatively good[26-27]. But there are other documents that do not support this viewpoint. Therefore, it is necessary to study the difference between $\mathrm{As}_{2}$ and As4 using in InGaAs materials epitaxy.

We use the residual gas analyzers in MBE system to judge whether the As beam is $\mathrm{As}_{2}$ or As 4 . When the cracking zone temperature is set to $950^{\circ} \mathrm{C}$, we investigated the effects of V/III ratio from 15 to 40 on the material quality using $\mathrm{As}_{2}$ mode. Fig.10 shows the electron concentration and mobility of $\operatorname{In}_{0.53} \mathrm{Ga}_{0.47}$ As epitaxial layer as a function of V/III ratio. The lowest carrier concentration is obtained at V/III ratio of 30, which is lower than samples using $\mathrm{As}_{4}$ mode. The highest electron mobility is obtained at V/III ratio of 20, which is higher than samples using $\mathrm{As}_{4}$ mode. Compared with the sample in $\mathrm{As}_{4}$ mode, Hall 
measurement shows that the $\operatorname{In}_{0.53} \mathrm{Ga}_{0.47} \mathrm{As}$ sample in $\mathrm{As}_{2}$ mode has better electrical performance.

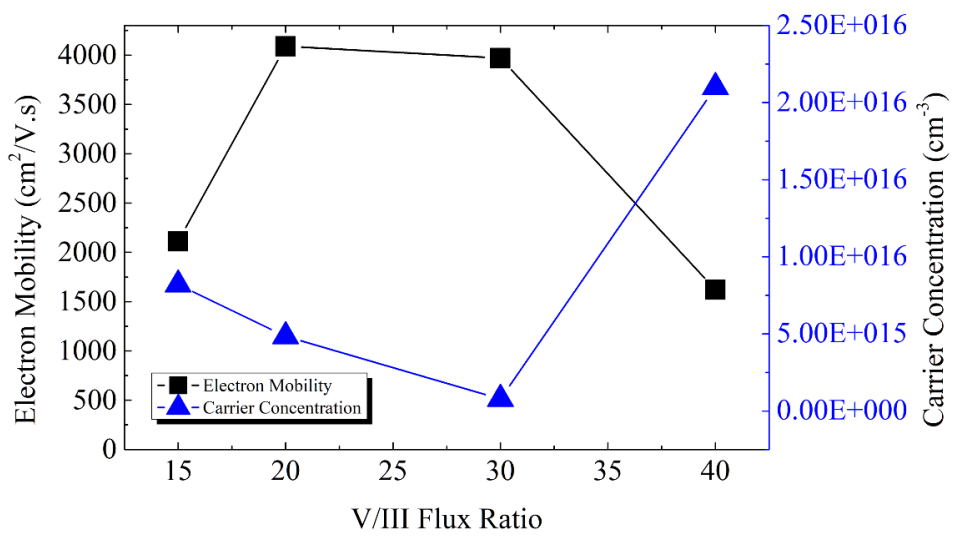

Fig. 10 electron mobility and concentration on $\operatorname{In}_{0.53} \mathrm{Ga}_{0.47} \mathrm{As}$ epitaxial layers using As 2 with V/III ratio from 20 to 40 .

In order to study the effect of arsenic cracker temperature on the electrical properties of $\mathrm{In}_{0.53} \mathrm{Ga}_{0.47} \mathrm{As}$, we changed the cracker temperature from $600^{\circ} \mathrm{C}$ to $950^{\circ} \mathrm{C}$. The relationship between the carrier concentration and mobility of $\operatorname{In}_{0.53} \mathrm{Ga}_{0.47} \mathrm{As}$ epitaxial layer obtained by hall test at room temperature and the temperature of arsenic cracking zone is shown in Fig.11. It can be seen that the highest mobility and highest electron concentration were obtained at cracker temperature of $830^{\circ} \mathrm{C}$. When the cracker temperature is $830^{\circ} \mathrm{C}$, the highest electron mobility is $5060 \mathrm{~cm}^{2} /(\mathrm{V} \bullet \mathrm{s})$, which is higher than that of $950^{\circ} \mathrm{C}$. The result showed that the mixed mode of $\mathrm{As}_{2}$ and $\mathrm{As}_{4}$ is helpful to improve the electron mobility of $\mathrm{In}_{0.53} \mathrm{Ga}_{0.47}$ As.

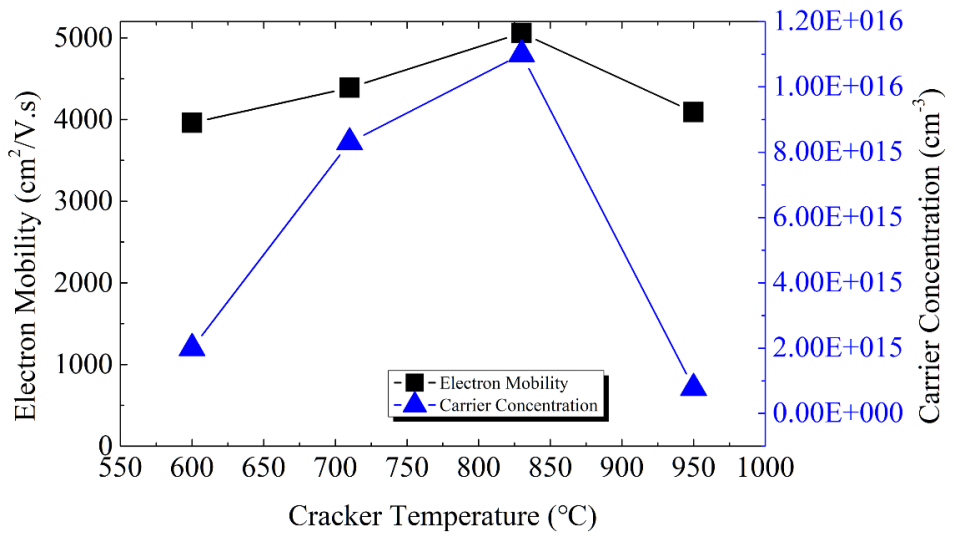

Fig. 11 electron mobility and concentration on $\operatorname{In}_{0.53} \mathrm{Ga}_{0.47} \mathrm{As}$ epitaxial layers with cracker temperature from $600^{\circ} \mathrm{C}$ to $950^{\circ} \mathrm{C}$.

Fig. 12 shows the $10 \times 10 \mu \mathrm{m}^{2}$ AFM micrographs obtained on the $\operatorname{In}_{0.53} \mathrm{Ga}_{0.47} \mathrm{As}$ epitaxial layers. The $\mathrm{In}_{0.53} \mathrm{Ga}_{0.47} \mathrm{As}$ layer grown with arsenic cracker temperature of $830^{\circ} \mathrm{C}$ has a mirror finish with RMS roughness of $0.204 \mathrm{~nm}$. 


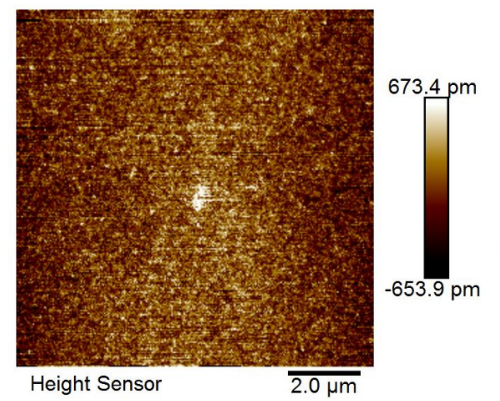

(a) Two dimensional AFM image

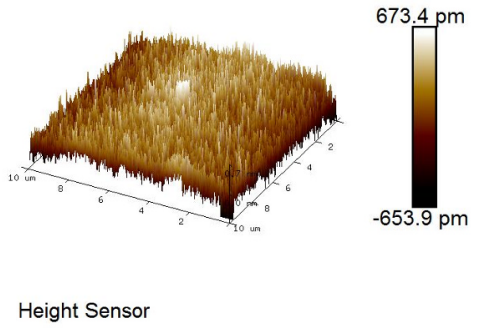

(b) Three dimensional AFM image

Fig. 12. AFM cartography of $10 \times 10 \mu \mathrm{m}^{2}$ scan area for the $\mathrm{In}_{0.53} \mathrm{Ga} 0.47 \mathrm{As}$ grown with arsenic cracker temperature of $830^{\circ} \mathrm{C}$.

\section{Conclusion}

In conclusion, we used molecular beam epitaxy system to epitaxial InP and InGaAs materials in phosphorus cracking cell and arsenic cracking cell, and studied the effects of epitaxial temperature and V/III ratio on the electrical properties and surface roughness of materials. The highest room temperature electron mobility of $3070 \mathrm{~cm}^{2} /(\mathrm{V} \cdot \mathrm{s})$ and the lowest electron concentration of $1.1 \times 10^{15} \mathrm{~cm}^{-3}$ were achieved in $\mathrm{InP}$ layers grown at $530^{\circ} \mathrm{C}$ and V/III ratio of 4.1. The effect of growth temperature and V/III ratio on $\operatorname{In}_{0.53} \mathrm{Ga}_{0.47} \mathrm{As}$ were also investigated. In As 4 mode, the highest electron mobility of $3960 \mathrm{~cm}^{2} /(\mathrm{V} \cdot \mathrm{s})$ was achieved in samples grown at V/III ratio of 65. However, in $\mathrm{As}_{2}$ mode, the highest electron mobility of $4090 \mathrm{~cm}^{2} /(\mathrm{V} \cdot \mathrm{s})$ was achieved in samples grown at V/III ratio of 20 . Samples with different cracker temperature of arsenic were grown to clarify the influence of arsenic species used in MBE growth. The results showed that the mixed mode of $\mathrm{As}_{2}$ and $\mathrm{As}_{4}$ is helpful to improve the electron mobility of InGaAs. We get the highest mobility of 5060 $\mathrm{cm}^{2} /(\mathrm{V} \cdot \mathrm{s})$ when the cracker temperature was set to $830^{\circ} \mathrm{C}$.

\section{Reference}

1. W. Dobbelaere, J. De Boeck, P. Heremans, R. Mertens, G. Borghs, W. Luyten, and J. Van Landuyt, Applied Physics Letters, 60, 868 (1992)

2. J. John, L. Zimmermann, S. Nemeth, T. Colin, P. Merken, S. Borghs, and C. V Hoof Proc, SPIE, 693 (2001)

3. K. Kurishima, H. Nakajima, T. Kobayashi, Y. Matsuoka, and T. Ishibashi, Applied Physics Letters, 62 (1993)

4. T. Nakano, M. Sugiyama, Y. Nakano, and Y. Shimogaki, Japanese Journal of Applied Physics, 47 (2008)

5. L. Jiang, T. Lin, X. Wei. Journal of Crystal Growth, 260 (2004)

6. G. B. Galiev, E. A. Klimov, S. S. Pushkarev, A. N. Klochkova, I. N. Trunkinb, A. L. Vasilievb, and P. P. Maltseva. Crystallography Reports, 62 (2017)

7. M. A. Stevens, S. Tomasulo, S. Maximenko, T. E. Vandervelde, and M. K. Yakes, Journal of Applied Physics, 121 (2017)

8. Z. G. Jie, S. Y. Chun, P. Biao, X. X. Dong, L. Y. Wang, Y. J. Hong, W. Z. Guo, Journal of Synthetic Crystal, 34 (2005) 
9. H. Asonen, K. Rakennus, K. Tappura, M. Hovinen and M. Pessa, Journal of Crystal Growth, 105 (1990)

10. T. Makimoto, K. Kurishima, T. Kobayashi, and T. Ishibashi. IEEE ELECTRON DEVICE LETTERS, 12 (1991)

11. Y. Fedoryshyn, M. Beck, P. Kaspar, and H. Jaeckel. Journal of Applied Physics, 107 (2010)

12. J. N. Baillargeon, A. Y. Cho, R. J. Fischer, P. J. Pearah, and K. Y. Cheng, Journal of Vacuum Science \& Technology B, 12 (1994)

13. T. Sugaya, A.Takeda, R.Oshima, K.Matsubara, S.Niki, Y.Okano, Journal of Crystal Growth, 378 (2013)

14. M. Natrella, E. Rouvalis, L. C. Pang, L. H. Yun, C. C. Renaud, and A. J. Seeds, Optics Express, 20 (2012)

15. K. L. Wan, H. T. Kian, W. Satrio, S. F. Yoon, M. H. Samuel, and Y. C. Yeo, J. Phys. D: Appl. Phys, 45 (2012)

16. R. France, A. J. Ptak, C. S. Jiang, and S. P. Ahrenkiel, Journal of Applied Physics, 107 (2010)

17. A. P. Mikhail, V. P. Valerii, R S Boris, Semicond. Sci. Technol, 24 (2009)

18. I. Hiromu, H. Yujiro, Y. Masatsugu, N. Yamamoto, T. Maruyama, and S. Naritsuka, Phys. Status Solidi C, 6 (2015)

19. N. Ramunas, C. Bronislovas, K. Julius, K. Vytautas, and E. H. Linfield, Nanoscale Research Letters, 7 (2012)

20. T. Sugaya, S. Furue, T. Amano, K. Komori, Journal of Crystal Growth, 301 (2007)

21. D. Huet, M. Lambert, D. Bonnevie, and D. Dufresne, Journal of Vacuum Science \& Technology B, 3 (1985)

22. H. Yong, H. R. Jae, D. D Russell, Journal of Crystal Growth, 321 (2011)

23. H. Toyoshima, T. Niwa, J. Yamazaki, and A. Okamoto, Appl. Phys. Lett, 63 (1993)

24. X. Zhou, Z. J. Luo, X. Guo, B. C. Zhang, L. T. Shang, Q. Zhou, C. Y. Deng, and Z. Ding, Chin. Phys. B, 21 (2012)

25. T. Suzuki, and T. Nishinaga, Journal of Crystal Growth, 111 (1991)

26. T. Yoriko, H. Shingo, H. Kentaro, M. Hitoshi, I. Noriaki, and U. Osamu, Journal of Crystal Growth, 544 (2020)

27. H. Z. Wang, Y. C. Zhu, Y. Gu, P. P. Chen, W. Wang, X. R. Chen, B. Yang, T. Li, and X. M. Shao, Materials Science in Semiconductor Processing, 112 (2020)

28. L. H. Li, G. Patriarche, E. H. Linfield, S. P. Khanna, and A. G. Davies, Journal of Applied Physics, 108 (2010)

29. P. M. Lytvyn, Y. I. Mazur, M Benamar, M.E. Ware, V.G. Dorogan, L.D. de Souza, E. Marega Jr, M.D. Teodoro, G.E. Marques, and G.J. Salamo, Applied Surface Science, 305 (2014) 